\title{
Correction to: Rapid acidolysis of benzyl group as a suitable approach for syntheses of peptides naturally produced by oxidative stress and containing 3-nitrotyrosine
}

\author{
Petr Niederhafner ${ }^{1,2} \cdot$ Martin Šafařík $^{2}$ - Eva Brichtová ${ }^{2}$ Jaroslav Šebestík ${ }^{2}$
}

Published online: 25 October 2019

(c) Springer-Verlag GmbH Austria, part of Springer Nature 2019

\section{Correction to: Amino Acids (2016) 48:1087-109 https://doi.org/10.1007/s00726-015-2163-2}

This errata is for paper "Rapid acidolysis of benzyl group as a suitable approach for syntheses of peptides naturally produced by oxidative stress and containing 3-nitrotyrosine" as published in Amino Acids, 2016, 48 (4):1087-1098.

Due to unit conversion error from $\mathrm{min}^{-1}$ to $\mathrm{s}^{-1}$, some of the published numbers have to be divided by 3600 . The conversion error affected not only our results, but also the conversion of published results concerning the acidolytic cleavage of tBu group (Lundt et al. 1978). Thus, some absolute values are different but the order of reaction rate and activation energy are consistent with published ones. The bigger difference occurred only for comparison of $\operatorname{Tyr}(\mathrm{Bn})$ vs. $\mathrm{Nit}(\mathrm{Bn})$ cleavage rates, i.e. instead of 2,000,000 times faster, the reaction is only ca 670 times faster. Nevertheless, after 30 min reaction time at $25{ }^{\circ} \mathrm{C}$, the benzyl group was cleaved from Fmoc-Nit(Bn)-OH with TFA more than 98\% (as it is visible from experimental data in Fig. 3, in published article). On the other hand, the right panel in Fig. 3-Arrhenius plot—had to be corrected. Since, the conversion error affected all rate constants, the activation energy remained the same. Moreover, the main message from the article stays valid and benzyl group is suitable protection for nitrotyrosine during the peptide synthesis using Fmoc/tBu strategy.

I apologize for this mistake.

\section{Corrections:}

Last two sentences in abstract should be: ... rate $\mathrm{k}=4.25 \times 10^{-3} \mathrm{~s}^{-1}$ at $20^{\circ} \mathrm{C}$. This rate is ca more than 670 times faster than that for cleavage of benzyl from $\operatorname{Tyr}(\mathrm{Bn})$.

The similar correction should be in the introduction section: This cleavage is ca 670 times faster than that from $\operatorname{Tyr}(\mathrm{Bn})$ (Erickson and Merrifield 1973).

In the results and discussion section: In the case of $\operatorname{Nit}(\mathrm{Bn})$, we have determined $k$ as $4.25 \times 10^{-3} \mathrm{~s}^{-1}$ at $20^{\circ} \mathrm{C}$. Thus, the cleavage of benzyl from $\mathrm{Nit}(\mathrm{Bn})$ proceeds more than 670 times faster than that from $\operatorname{Tyr}(\mathrm{Bn}) . .$. Interestingly, since cleavage of tert.-butyl from Z-Tyr(tBu)-OH proceeded with $k 8.67 \times 10^{-4} \mathrm{~s}^{-1}$ (Lundt et al. 1978), ...

Values of rate constants were corrected in Table 2:

The original article can be found online at https://doi.org/10.1007/ s00726-015-2163-2.

Jaroslav Šebestík

jsebestik@seznam.cz; sebestik@uochb.cas.cz

1 Department of Chemistry of Natural Compounds, Faculty of Food and Biochemical Technology, University of Chemistry and Technology, Prague, Technická 5, 16628 Prague 6, Czech Republic

2 Institute of Organic Chemistry and Biochemistry, Academy of Sciences, Flemingovo náměstí 2, 16610 Prague 6,

Czech Republic 
Table 2 Reaction rates of protection group cleavage and energies of model cation formation

\begin{tabular}{|c|c|c|c|c|c|c|c|}
\hline \multirow[t]{3}{*}{ Reactant } & \multirow[t]{3}{*}{$k\left[\mathrm{~s}^{-1}\right]^{\mathrm{b}}$} & \multicolumn{6}{|c|}{$\Delta E\left[\mathrm{kcal} \mathrm{mol}^{-1}\right]^{\mathrm{a}}$} \\
\hline & & \multicolumn{3}{|c|}{ Protonation } & \multicolumn{3}{|c|}{ Cleavage } \\
\hline & & TFA & $\mathrm{HCl}$ & $\mathrm{HBr}$ & TFA & $\mathrm{HCl}$ & $\mathrm{HBr}$ \\
\hline $\operatorname{Tyr}(\mathrm{Bn})$ & $6.36 \times 10^{-6}\left({ }^{c}\right)$ & 42 & 33 & 30 & 7 & 7 & 7 \\
\hline $\operatorname{Nit}(\mathrm{Bn})$ & $4.25 \times 10^{-3} \mathrm{~s}^{-1}$ & 33 & 25 & 22 & 8 & 8 & 8 \\
\hline $\operatorname{Tyr}(\mathrm{tBu})$ & $8.67 \times 10^{-4} \mathrm{~s}^{-1}\left({ }^{\mathrm{d}}\right)$ & 36 & 27 & 24 & 8 & 8 & 8 \\
\hline
\end{tabular}

${ }^{\text {a }}$ Reaction: reactant + acid $\rightarrow$ protonated cation + anion $\rightarrow$ product + anion + cleaved cation

${ }^{b}$ In TFA

${ }^{c}$ Erickson and Merrifield (1973) and Tam et al. (1983)

${ }^{\mathrm{d}}$ Lundt et al. (1978)

Right panel in Fig. 3 and label were corrected:
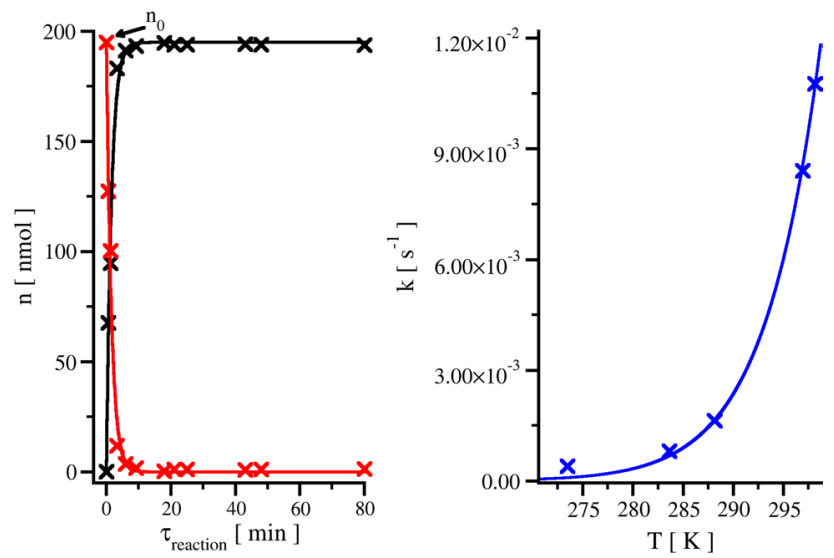

Fig. 3 Kinetic of benzyl removal from Fmoc-Nit(Bn)-OH with ca $80 \%$ TFA at $25{ }^{\circ} \mathrm{C}$ (left). The amount of Fmoc-Nit(Bn)-OH (1) and Fmoc-Nit-OH (2) are shown with red and black color, respectively. The data were fitted with first-order kinetic providing $k$ $1.08 \times 10^{-2} \mathrm{~s}^{-1}$. The dependence of rate constant on temperature (right) was fitted by Arrhenius equation. The activation energy from the fit is $32 \mathrm{kcal} \mathrm{mol}^{-1}$
Values were corrected in Supplementary Figure 2:

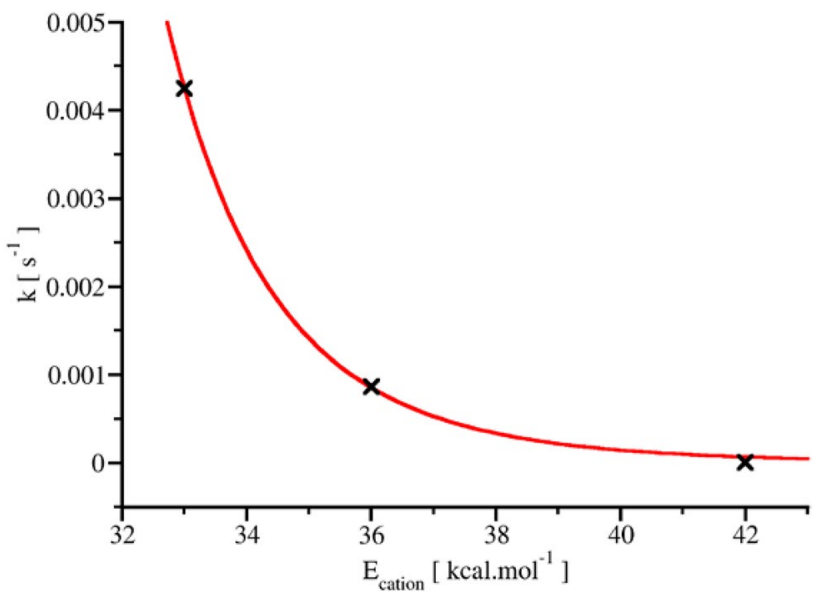

Figure SI 2 Correlation between calculated energy of cation formation and reaction rate of protection group cleavage in TFA. $k=A * e^{\frac{B}{E_{\text {cation }}}}$ with $A=1.84 \times 10^{-11} \mathrm{~s}^{-1}, B=636 \mathrm{~mol} \mathrm{kcal}^{-1}$, and correlation coefficient 0.99988

Publisher's Note Springer Nature remains neutral with regard to jurisdictional claims in published maps and institutional affiliations. 